\title{
SIZE DISTRIBUTION AND SORTING DEGREE OF THE RECENT SEDIMENTS OF AL-KHAZER RIVER/ NORTHERN IRAQ
}

Khalid F. Hassan

Soil and Water Resources Dept./ College of Agri. and Forestry /Mosul Univ. /Iraq

\begin{abstract}
Mechanical and statistical analysis were conducted to determine the grain size distribution and sorting degree of the recent sediments of Al-Khazer river at northern of Iraq in order to clarify the sedimentation processes along this river. The study was carried out after the annual flood time of the river. Sediment size distribution was determined mechanically for major grain size fractions [gravel ( -2 phi to 0 phi), sand ( 0 phi to +4 phi), silt ( +5 phi to +7 phi)] and clay ( +8 phi)] using sieve and pipette technique. Numerical treatment of grain size curves has been done on the basis of some quintiles read from the empirical cumulative distribution function (CDF) curve: phi median size, sorting, skewness and kurtosis.

The results showed that the sediments of this river were relatively coarse grained textured $\left(\varnothing_{50}=0.35\right.$ to $\left.1.2 \mathrm{phi}\right)$, very poorly sorted, showing strongly coarse skewed towards fine particles and are platy to leptokurtic. The increase in phi toward outlet plain is equivalent to decrease in grain diameter and is indicative of a lower energy and higher depositional environment. For this reason, there are some relatively lower phi values in the inlet plain in comparison with the phi values of outlet plain. On the basis of this assumption, the change in sediment-size distribution along the river is a non-linear fashion and can be inferred from that to which the present deposition takes place by bed or graded suspended load.
\end{abstract}

\section{INTRODUCTION}

The process of both erosion and sedimentation were in a dynamic state along the river during flooded time. As the rivers move they carry soil, sand, and sediment along with them. The sediments which transport actually play an important role in shaping the environment (Ramish and Subramenntan, 1992).

Most researches on sediments, grain-size data are given in term of phi (Ø) intervals rather than in microns, millimeters, or inches. Phi diameter is computed by taking the negative logarithm to the base 2 of the particle size diameter in millimeters (Folk 1980) according to;

$$
\varnothing=-\log _{2} d(\mathrm{~mm})=-\log _{10} \mathrm{~d} / \log _{10} 2=-3.3219 \log _{10} \mathrm{~d}
$$

Where ;

$\varnothing=$ grain diameter in term of $\varnothing$ unit and

$\mathrm{d}=$ grain diameter in $\mathrm{mm}$

The normal progression of sediment-grain sizes in $\mathrm{mm}$ and phi units from the Wentworth scale are shown in table 1. It is important to remember as shown in this table that as grain-size gets smaller, phi gets bigger, and statistical computations and graphic presentations be much simpler when phi diameters are used. (Inman, 1982): Sediments can be divided into two components on the basis of the mode of sediments transport: suspended sediment, and bedload sediment. Suspended 
Table ( 1 ): The normal progression of sediment-grain sizes in $\mathrm{mm}$ and phi units from the Wentworth scale.

\begin{tabular}{|l|c|c|c|c|c|c|c|c|c|}
\hline $\mathrm{mm}$ & 2 & 1 & 0.5 & 0.25 & 0.125 & 0.064 & 0.032 & 0.016 & 0.008 \\
\hline Phi $(\phi)$ & -1 & 0 & 1 & 2 & 3 & 4 & 5 & 6 & 7 \\
\hline
\end{tabular}

sediment consists of silt-sized and clay-sized particles held in suspension as flow is turbulent. Bedload sediment consists of particles larger than sand- size which slide, roll, or bounce along the streambed by the force of moving water (Al- Ramanathan et al.,2009).

The sources of sediment are varied, and the present distribution is the result of a complex interaction of modern, active sediment-erosion interaction processes (Irion and Zöllmer, 1999). When a river is dammed, the sediments that used to flow along with the relatively fast-moving river water are deposited in the depressions. This happens because the river water flowing through the lowland moves too slowly to keep sediment and suspended to settles at the bottom according to Stokes' Law which states that (Wilcock, et al 2001 ):

$$
\mathrm{V}=\frac{\left(\mathrm{P}_{\mathrm{S}}-\mathrm{P}_{\mathrm{w}}\right)}{---\mathrm{g} \mathrm{d}^{2}}
$$

Where ;

$$
\begin{aligned}
\mathrm{V} & =\text { the velocity at which the grain is falling }(\mathrm{cm} / \mathrm{s}) \\
\mathrm{g} & =\text { the acceleration due to gravity }=980 \mathrm{~cm} / \mathrm{s}^{2} \\
\mathrm{~d} & =\text { the particle diameter }(\mathrm{mm}) \\
\mathrm{n} & =\text { the dynamic viscosity of the liquid (poise) }
\end{aligned}
$$

$\mathrm{P}_{\mathrm{S}}$ and $\mathrm{P}_{\mathrm{w}}=$ the mass density of sediment grain and water respectively $\left(\mathrm{g} / \mathrm{cm}^{3}\right)$.

The U.S. Geological Survey does quite a lot of work measuring how much sediment is transported by streams. To do this, both the amount of bed and suspended sediments in that stream water must be measured. Both bed and suspended sediment concentration are continually changed during a storm, hydrologists take measurements of how much sediment is in the water at different stream flows (Eisma 1991, Ry 2002).

Because soil and sediments scientists have long understood the importance of particle size distribution to their field and predicting behavior, the present study was carried out to asses the magnitude of variation in grain size distribution of recent sediments in the Al-Khazer river by using a mechanical and statistical parameters to understand better the sedimentation processes along this river and to determine whether these processes limit the efficiency of agricultural soils of adjacent areas. Sediments-grain size information can also be used in conjunction with current velocity data to predict whether the sediments is more likely to deposit in the river bed or to be transported downstream.

\section{MATERIALS AND METHODS}

The study was conducted at Alkhazer river, which is a midstream tributary of the Greater Zab river/northern Iraq. The river watershed is sandwiched between 
Latitude $36^{\circ} 00^{-} 20 \mathrm{~N}$ and Longitude $43^{\circ} 00^{-} 08 \mathrm{E}$ with length of $426 \mathrm{Km}$ and ranges in elevation from 222 to $425 \mathrm{~m}$. Sandston makes up the bedrock.

Al-Khazer river, originates from mountainous area and flows in the northern sections through the mountainous terrain and deep valleys with flow path has a decline ranged between 5-8\%. After passing the Bakhma site where the proposed dam site (dam of Bakhma), the river flow being in the land plain and is be set with many sandy islands covered by the waters during the flooded seasons. The water level of the Greater Al-Zab river depend primarily on the basic water level of AlKhazer river. When Al-Khazer river comes primarily in term of its contribution to the Greater Al-Zab river, the water had reach the maximum annual rate of discharge up to $215 \mathrm{~m}^{3} / \mathrm{s}$ and lead to an increase in the presentation of the river course so that the main display up to $(600 \mathrm{~m})$.

Sediment samples from inlet and outlet flood plains of Al-Khazer river were collected after the annual flood of the river. The Sediment samples (50gm), after dried, were separated mechanically for major grain size fractions [ gravel ( -2 phi to 0 phi), sand ( 0 phi to +4 phi), silt ( +5 phi to +7 phi)] and clay ( +8 phi $)]$. Coarsefraction size distribution (Sand and gravel) were determined by using the standard sieving techniques (Folk 1980). Fine -fraction size distribution down to +4 phi (Silts and clays) were measured in each sample by sedimentation (pipette technique) as described by Torresan et. al (1997). The weight of sediment of each size was measured and converted into a percentage of the total sediment sample. The grain size distribution as determined by sieve and pipette technique was normally presented as a Cumulative Frequency Distribution (CDF) curve plot ( Fig 1).

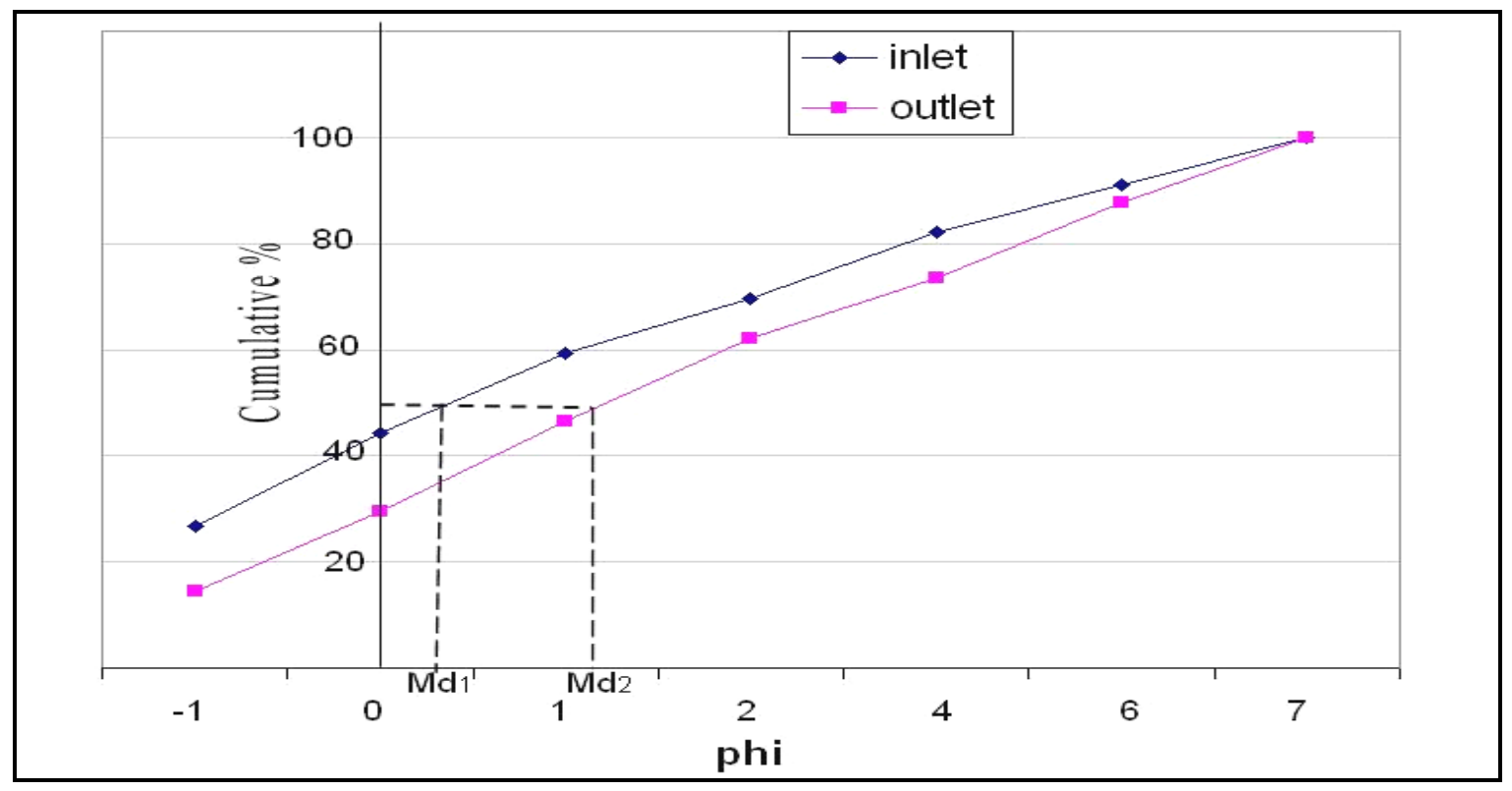

Fig (1).Cumulative frequency curve for grain size distribution of the river plain

In all of these plots, grain size is plotted on the horizontal scale and percentage on the vertical scale. The coarsest grain size is always plotted on the left and finest on the right. The reverse of the usual convention, though in the phi scale the coarsest 
grain sizes have lower numbers, typically negative numbers where fine grain sizes have higher numbers. Percentages were plotted so as to increase upward on the diagram. From these plotting, the sediment-grain size distribution was evaluated by calculating the graphic statistical parameters (phi median size, sorting, skewness and kurtosis,) on the basis of Folk (1980) classification and formulas as in the following;

(1)- A measure of central tendency (Ø50); Commonly used the median phi value (Ø50); which is the value of phi corresponding to $50 \%$ on the cumulative frequency curve. Its interpretation $\left(\mathrm{Md}_{1}\right.$ and $\left.\mathrm{Md}_{2}\right)$ is shown by the figure (1) which is the value of phi, $\square$ corresponding to $50 \%$ in the cumulative frequency curve.

(2) - A measure of degree of scatter (Sorting): It is a measure of the uniformity or homogeneity of the sediment which can be obtained from the inclusive graphic standard deviation as follow:

$$
\varnothing_{\mathrm{I}}=\left(\varnothing_{84}-\varnothing_{16}\right) / 4+\left(\varnothing_{95}-\varnothing_{5}\right) / 6.6
$$

The value can be interpreted by using the table ( 2 ),

Table ( 2 ): Sorting degree of sediment- grain size in relation to phi value

\begin{tabular}{|c|c|}
\hline $\boldsymbol{\emptyset}_{\text {I }}$ & Degree of Sorting \\
\hline less than 0.35 & Very Well Sorted \\
\hline 0.35 to 0.50 & Well Sorted \\
\hline 0.50 to 1.00 & Moderately Sorted \\
\hline 1.00 to 2.00 & Poorly Sorted \\
\hline 2.00 to 4.00 & Very Poorly Sorted \\
\hline more than 4.00 & Extremely Poorly Sorted \\
\hline
\end{tabular}

3- A measure of skewness ( lack of symmetry ); The skewness of each normal distribution refers to the slope of log scale distribution whether symmetrical, positively or negatively skewed. The symmetrical distribution indicates that the different sizes of sediments are similarly distributed. Skewness can be determined as follow ( Folk ,1980):

$$
\begin{aligned}
& \left(\varnothing_{84}+\varnothing_{16}-\varnothing_{50}\right) \quad\left(\varnothing_{95}+\varnothing 5-\varnothing_{50}\right) \\
& \mathrm{Sk}=\mathrm{-} 2\left(\varnothing_{84}-\varnothing_{16}\right) \quad 2\left(\varnothing_{95}-\varnothing_{5}\right)
\end{aligned}
$$

The results can be interpreted from the table (3):

Table(3):Degree of graphic skewness( Sk) of sediment in relation to phi value.

\begin{tabular}{|c|l|}
\hline Sk & \multicolumn{1}{c|}{ Skewness } \\
\hline 1.00 to 0.30 & Strongly skewed towards fine particles \\
\hline 0.30 to 0.10 & Fine Skewed \\
\hline 0.10 to -0.10 & Symmetrical \\
\hline-0.10 to -0.30 & Coarse Skewed \\
\hline-0.30 to -1.00 & Strongly skewed towards coarse particles \\
\hline
\end{tabular}


(4) - A measure of the degree of "peakedness (Kurtosis): Kurtosis assesses the percent of frequency distribution of particle sizes in terms of a different sort of departure from the normal distribution. If the distribution is excessively peaked it is called leptokurtic; if it is flattened, it is called platykurtic. This parameter clarify the range of particle sizes in the sediment sample. Kurtosis can be determined as follow of (Folk ,1980):

$$
\mathrm{K}_{\mathrm{G}}=\left(\varnothing_{90}-\emptyset_{10}\right) / 2.44\left(\varnothing_{75^{-}} \varnothing_{25}\right)
$$

The results can be interpreted from the table (4):

Table(4): Degree of Kurtosis ( $\mathrm{K}_{\mathrm{G}}$ ) of sediment in relation to phi value.

\begin{tabular}{|c|c|c|}
\hline \multicolumn{2}{|c|}{$\mathrm{K}_{\mathrm{G}}$} & Kurtosis \\
\hline less thar & 0.67 & Very Platy- Kurtic \\
\hline 0.67 tc & 0.90 & Platy-Kurtic \\
\hline 0.90 to & 1.11 & Mesokurtic (nearly normal) \\
\hline 1.11 to & 1.50 & Leptokurtic \\
\hline more tha & 1.50 & Very Leptokurtic \\
\hline
\end{tabular}

\section{RESULTS AND DISCUSSION}

Tables (5 and 6) refer to the total mass percentage of size distribution for inlet and outlet flood plains of Alkhazer river. It revealed that the sediments in the both flood plains were relatively coarse grained and its value range from 73.4 to $82.0 \%$ of fraction less than 4 phi in diameter at inlet and outlet flood plain respectively. This result indicated that the sedimentlogical characteristics of Alkhazer river, like most other rivers environments, which dependent upon the combination effectiveness of physical forces of active sediment-erosion interaction processes (Kamaruzzaman 1994).

Table(5): \% Sediment-grain size analysis for the inlet plain of Al-Khazer river

\begin{tabular}{|c|c|c|c|c|c|}
\hline Size name & $\begin{array}{c}\text { grain size } \\
\mu \mathrm{m}\end{array}$ & $\begin{array}{c}\text { grain size } \\
\text { Phi }\end{array}$ & $\begin{array}{c}\text { Weight of Size } \\
\text { Fraction }(g)\end{array}$ & $\begin{array}{c}\text { Weight } \\
\text { Percent } \\
\%\end{array}$ & $\begin{array}{c}\text { Cumulative } \\
\text { weight \% } \\
\text { greater than }\end{array}$ \\
\hline gravel & $>2000$ & -1 & 12.8 & 25.6 & 25.6 \\
\hline v. coarse sand & $>1000$ & 0 & 9.3 & 18.6 & 44.2 \\
\hline coarse sand & $>500$ & 1 & 7.6 & 15.2 & 59.4 \\
\hline Fine sand & $>125$ & 3 & 5.1 & 10.2 & 69.6 \\
\hline V. Fine sand & $>64$ & 4 & 6.2 & 12.4 & 82.0 \\
\hline Silt & $>0.16$ & 6 & 4.8 & 9.6 & 91.6 \\
\hline Clay & $>8$ & 7 & 4.2 & 8.4 & 100 \\
\hline
\end{tabular}

The increase in phi is equivalent to decrease in grain diameter in $\mathrm{mm}$ and is related to a lower energy or higher depositional environment. For this reason ,the sediment- grain size of inlet plain show some relatively lower phi values compared to the outlet plain. Reduction in the size of sediment materials with distance downstream is commonly observed in gravel and sand -bed river. Tables 5 and 6 
shows that the gravel -size fraction are predominate in the inlet plain ( $25.6 \%$ ) compared with sediments of outlet plain which is about ( $14.6 \%$ ) gravel. Candic et al. (2003) have attributed this feature (termed Down Stream Finning) to the processes of selective sorting and abrasion.

Table(6) : \%Sediment-grain size analysis for the outlet plain of Al-Khazer river

\begin{tabular}{|c|c|c|c|c|c|}
\hline Size name & $\begin{array}{c}\text { grain } \\
\text { size } \\
\mu \mathrm{m}\end{array}$ & $\begin{array}{c}\text { grain size } \\
\text { Phi }\end{array}$ & $\begin{array}{c}\text { Weight of } \\
\text { Size } \\
\text { Fraction }(\mathrm{g})\end{array}$ & $\begin{array}{c}\text { Weight } \\
\text { Percent } \\
\%\end{array}$ & $\begin{array}{c}\text { Cumulative } \\
\text { weight \% } \\
\text { greater than }\end{array}$ \\
\hline gravel & $>2000$ & -1 & 7.3 & 14.6 & 14.6 \\
\hline V. Coarse sand & $>1000$ & 0 & 7.4 & 14.8 & 29.4 \\
\hline Coarse sand & $>500$ & 1 & 8.5 & 17.0 & 46.4 \\
\hline Fine sand & $>125$ & 3 & 7.8 & 15.6 & 62.0 \\
\hline V. Fine sand & $>64$ & 4 & 5.7 & 11.4 & 73.4 \\
\hline Silt & $>0.16$ & 6 & 7.2 & 14.4 & 87.8 \\
\hline Clay & $>8$ & 7 & 6.1 & 12.2 & 100 \\
\hline
\end{tabular}

On the basis of this assumption, the general distribution of silt/clay proportion in the two flood plains were approximately similar ( 1.14 and 1.18 ) and show small change towards the outlet site. This may indicate that the grains transporting capacity of the river decreases toward the outlet which causing a sudden deposition of coarse and fine sand from the bed load sediments. This process lead to a new sand deposits which covering the old coarse sandy sediments. The arrangement of these deposits starts from the top of either fine sediments and ends by coarse or started by coarse and ended by the fine sediments as a result of the river recession (Blott and Pye, 2001) .

The distribution patterns of the two plains in each class (gravel, sand, silt and clay can be shown graphically as a bar chart in Fig 2. It appears that the inlet plain was dominated by coarse grained (gravel) textured while the texture at the outlet plain was much finer, reflecting a uni-modal distribution with low-energy depositional environment.

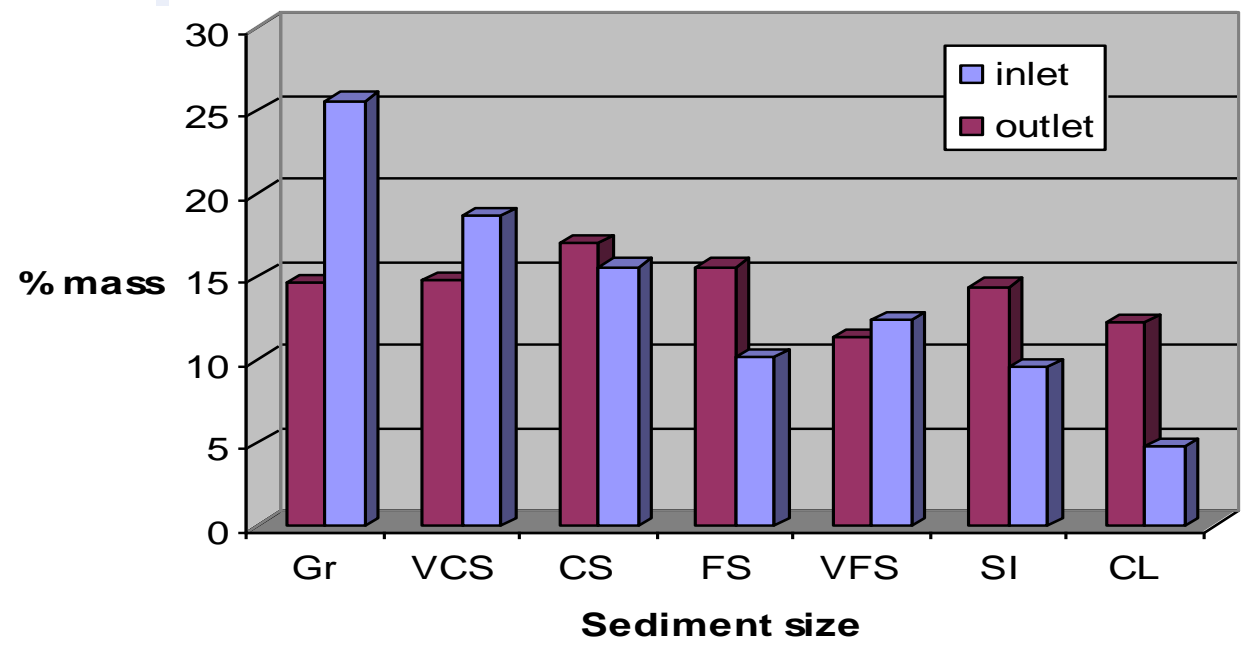

Fig(2):The Uni-modal sediment-size distribution for both river plains 
To facilitate comparison among size distributions, we commonly develop a statistics parameters extracted from the cumulative frequency curves of Fig (1) and presented in table (7). The graphical median weight diameter, $(\mathrm{Md}=\varnothing 50$ as the line on the graph 1 which show the phi value at 50\%) is commonly used in hydrology, geomorphology, and engineering as a measure of central tendency of the distribution because it is easily read from distributions and unambiguously interpreted (Inman 1982).

Table (7): Statistical parameters of grain size analysis for the both river plains

\begin{tabular}{|c|c|c|c|c|c|}
\hline Site & Parameters & $\begin{array}{c}\text { Graphical } \\
\text { Median } \\
(\varnothing 50)\end{array}$ & $\begin{array}{l}\text { Sorting } \\
\text { (So) }\end{array}$ & $\begin{array}{l}\text { Skewness } \\
\text { (Sk) }\end{array}$ & $\begin{array}{c}\text { Kurtosis } \\
\left(\mathrm{K}_{\mathrm{G}}\right)\end{array}$ \\
\hline \multirow[t]{2}{*}{ Inlet } & Value & 0.35 & 2.29 & 0.64 & 0.87 \\
\hline & Class & Coarse sand & $\begin{array}{l}\text { very poorly } \\
\text { sorted }\end{array}$ & $\begin{array}{c}\text { Skewed } \\
\text { towards fine } \\
\text { particles }\end{array}$ & Platy -Kurtic \\
\hline \multirow[t]{2}{*}{ Outlet } & Value & 1.20 & 2.05 & 0.30 & 0.73 \\
\hline & Class & Very fine sand & $\begin{array}{c}\text { very poorly } \\
\text { sorted }\end{array}$ & $\begin{array}{c}\text { Skewed } \\
\text { towards fine } \\
\text { particles }\end{array}$ & Platy-Kurtic \\
\hline \multirow[t]{2}{*}{ Mean } & Value & 0.77 & 2.17 & 0.47 & 0.80 \\
\hline & Class & Fine sand & $\begin{array}{l}\text { very poorly } \\
\text { sorted }\end{array}$ & $\begin{array}{c}\text { Skewed } \\
\text { towards fine } \\
\text { particles }\end{array}$ & Platy-Kurtic \\
\hline
\end{tabular}

The values of graphical median weight diameter (Ø50) appears to be low( 0.35 phi) in the inlet plain ( equal to grain diameter of very coarse sand ) in comparison with the median weight diameter (1.20phi ) of outlet plain ( which equal to grain diameter of coarse sand.. Gravelly sands and sandy gravels predominated in the two plains, reflected a larger median grain sizes and more poorly sorted sediments. Table 7 shows that the coefficient of sorting for both plains are very poorly . This result reveals that there is confusion in all sizes of sediment in both plains and can not be separated from each other. The unchanging sorting values from inlet to outlet plain indicate that fine sediments are deposited under the prevailing low energy conditions. The relationship between median size, sorting and porosity probably results from the fact that larger grains have a higher sphericity and tend to pack more closely together than smaller, more irregularly shaped grains. Porosity is independent of median size in well sorted sands but appears to be decrease slightly with increasing median size in poorly sorted sands. Many sediments are characterized by larger particles that make up the structure of the deposit with finer sediments filling the pore spaces between the framework grains (the matrix).Some sediments contain so much matrix that most framework grains are not touching and thus are not carrying the weight of the deposit; these are termed "matrixsupported" deposits(Blott, and Pye, 2001). 


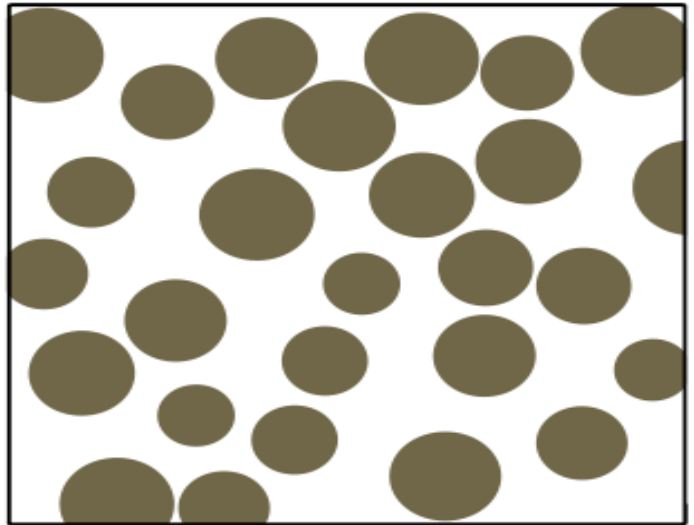

A

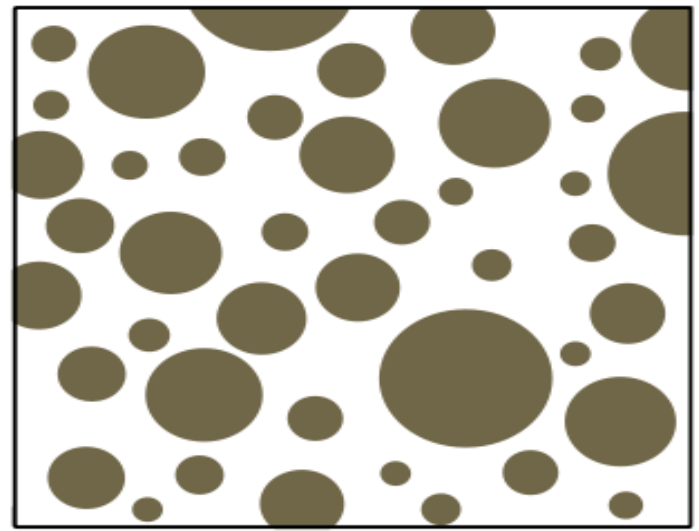

B

Fig( 3 ): Schematic diagram showing sorting of grain size distribution, (A) well - sorted sediments and ( B ) poorly sorted sediments

On the other hand, the inclusive graphic skewness refers to how much the distribution is skewed off a normal or lognormal distribution. It is commonly calculated as the geometric skewness coefficient (Sk). Results indicated that skewness of AlKhazer sediments showed no variation between the two sites. The two sites had a wide range from positive skewness ( $0.64 \mathrm{phi})$ at the river inlet to positive skewness (0.30phi) at the river outlet indicating strongly skewed toward fine grains in both studied plains( Fig.4-B). A positive skewness means that there is an excess of fine grain sizes which could be due either to the addition of fine sediment to the deposits or to the selective removal of the coarser grain ( Kamaruzzaman, 2008).

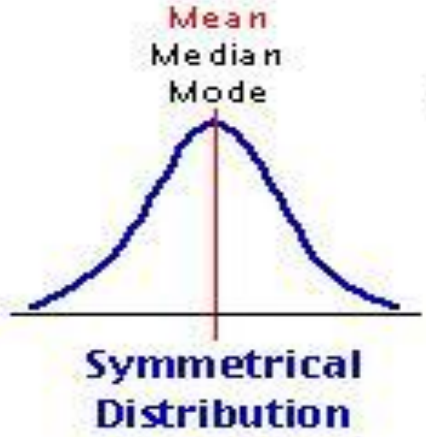

A

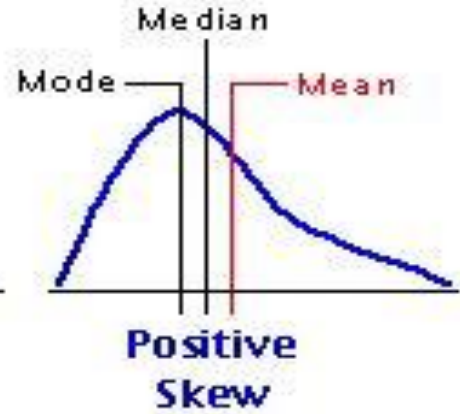

B

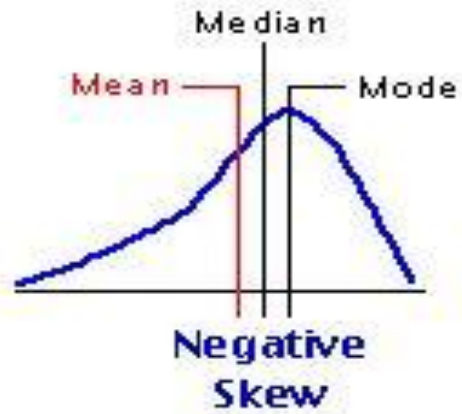

$\mathrm{C}$

Fig.( 4 ): Patterns of inclusive graphic skewness in relation to size distribution

According to the Inman formula , the peakedness of the fourth moment kurtosis $\left(\mathrm{K}_{\mathrm{G}}\right.$ ) of the sediments was found to be varies from $0.87 \mathrm{phi}$ in the inlet plain to 0.73 of the outlet indicating the dominance of coarser size of platy kurtic nature of sediment. Extreme high values of phi kurtosis imply that a part of the sediments achieved its sorting elsewhere a high energy environment variation. (as in this case) reflecting the majority of sand. This may be due to aggregation of sediment particle size by compaction or variation in sorting values due to continuous addition of finer/coarse materials in varying proportioned medium(Al-Ramanathan et al. 2009). 


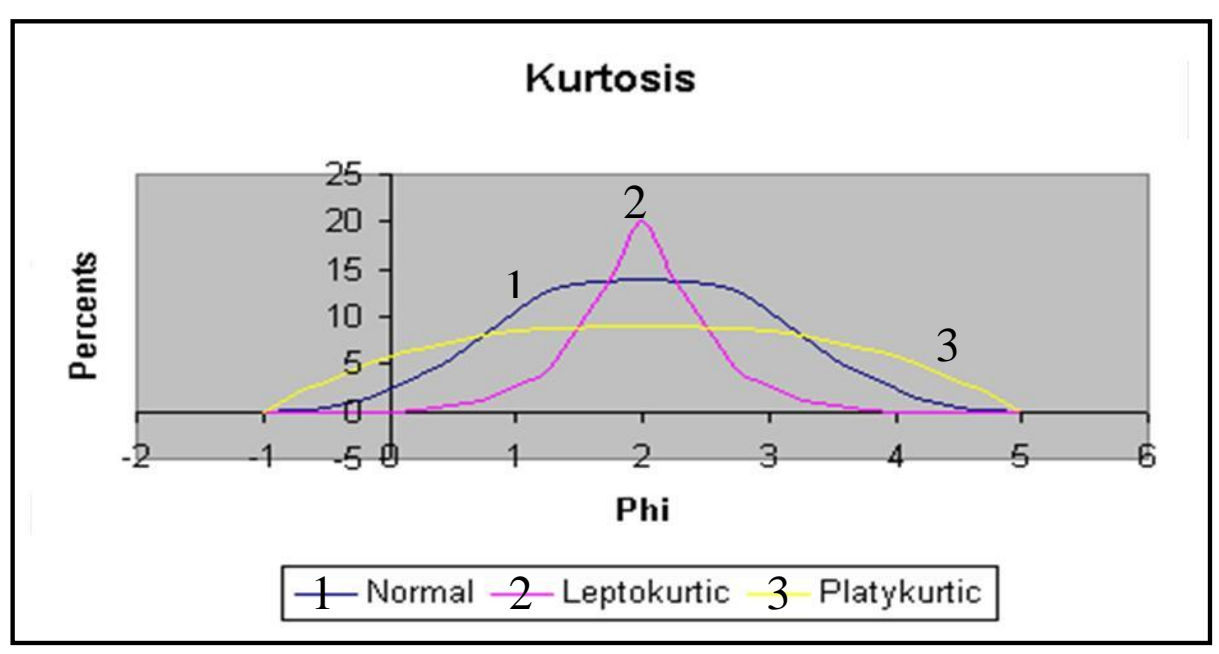

Fig.( 5 ): Patterns of inclusive graphic kurtosis in relation to size distribution

Although further attempt may be made to interpret these values, due to low sampling density of the study area, interpretation based on skewness and kurtosis, which are third and fourth statistics, respectively, is considered to be unreasonable. This result coming in agreement of Ramish and Subramenntan (1992) when they studied the sediment size distribution of Krishna river. They reported that the sediments are mostly coarse sand (0.35 phi) to very fine sand (1.2 phi), very poorly sorted, showing strongly skewed toward fine particles (negatively skewed) and are platy - kurtic.

Thus, it was possible to conclude that there is a similarity in sediment-grain size distribution in both studied river sites. This means that the river is in a recession state which leading to a continuous deposition of sediments phones during the winter. The grain size of sediments of this river always is in a dynamic state, coarser sediments being gradually replaced by finer sandy or silty sediments toward outlet plain which may due to different types of sediments that contributed by tributaries to the river. On the basis of this assumption, the change in sediment-size distribution along the river is in a non-linear fashion and the present deposition takes place by bed or graded suspended load. The comparison between the sediments in both plains needs to analyze other statistical parameters more deeply to the field dealt with parameters used in this study.

$$
\begin{aligned}
& \text { التوزيع ألحجمي ودرجة الفرز لرواسب نهر الخازرالحديثة التكوين / شمال العراق }
\end{aligned}
$$

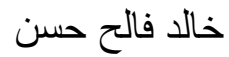

$$
\begin{aligned}
& \text { قسم علوم التربة والموارد المائية / كلية الزراعة والغابات /جامعة الموصل / العراق }
\end{aligned}
$$

\section{الخلاصة}

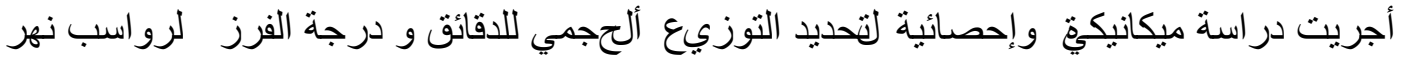

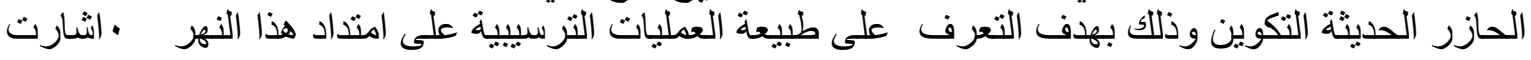
النتائج إلى سيادة الدقائق الخشنة (

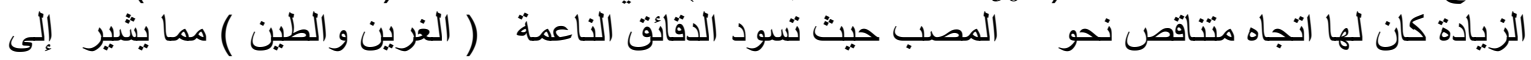




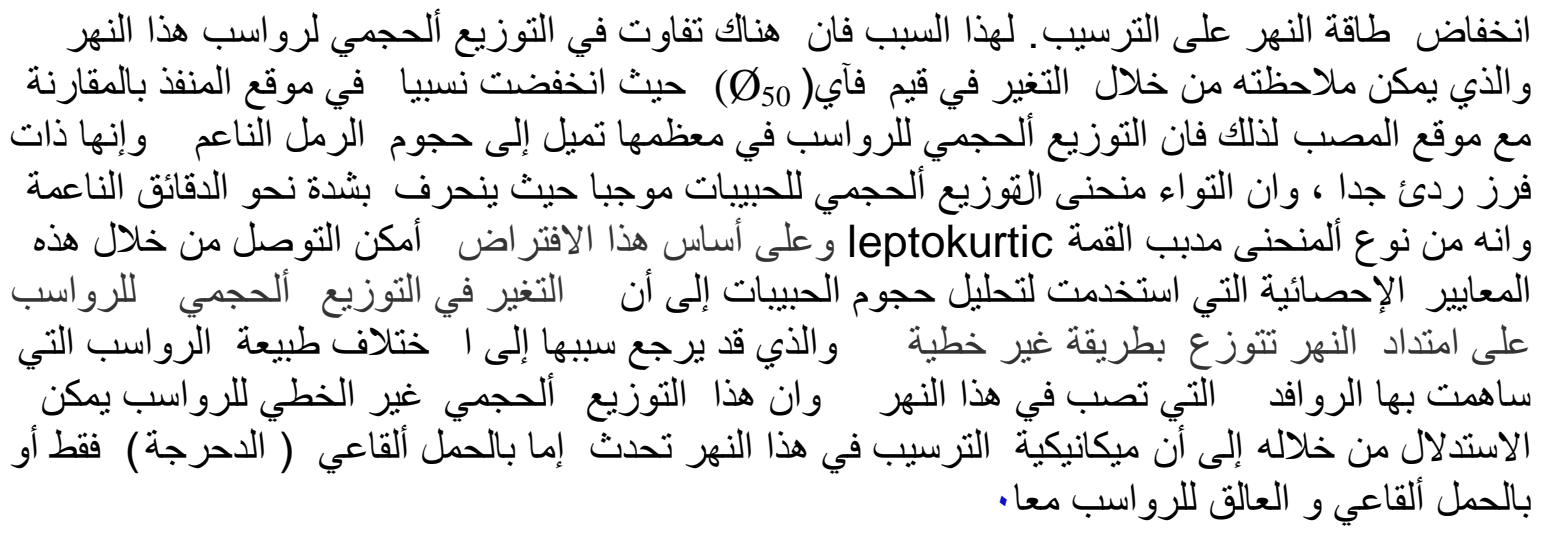

\section{REFERENCES}

Al- Ramanathan, K., A. Rajkurar, J. Majumdarar ,G. Singh ,P. Behera (2009). Textural characteristics of the surface sediments of a tropical mangrove Sundarban ecosystem Indian .J. of Marin Sci. 38: 397- 403.

Blott, S., and K. Pye, (2001). A grain size distribution and statistics package for the analysis of unconsolidated sediments. Earth Surfaces Proc. 26: 1237-1248.

Candic , R., J. Mount and J. Florsheim ( 2003) . The effect of longitudinal differences in gravel mobility in the Gosumnes river .J. of Geo.111: 23-41

Eisma, D.( 1991). Supply and deposition of suspended matter in the North Sea. Special Publ. of the Inter. Association of Sedimentologists, 5: 415-428.

Folk, R.L.. (1980). Petrology of Sedimentary Rocks: Austin, Texas, U.S.A., Hemphill Publishing Co., 2nd edition, $184 \mathrm{p}$

Inmann, D.L.(1982). Measures for describing the size distribution of sediments. Journal of Sedimentary Petrology. 22 : 125-145.

Irion, G., and V. Zöllmer ( 1999). Clay mineral associations in fine-grained surface sediments of the North Sea. Journal of Sea Research, 41: 119-128

Kamaruzzaman B.Y and M.C. Ong ( 2008) . Recent sedimentation rate and sediment ages determination of Kemaman-Chukai Mangrove forest , Malaysia American J. of Agric. and Biol. Sci. 3 : 522-525 .

Ramish, R., and R. Subramenntan ( 1992) .Textural characteristics of Kirshana river /India Geo. Journal , 28 : 542-551.

Ry, K., N. Shazili, and H. Mohd (2002). Particle size distribution in the bottom sediments of the Kemaman river, Malaysia J. Agric. Sci. 25: 149 - 155 .

Torresan, M.(1997). A review and comparison of the hydrometer and pipette methods in the analysis of fine-grained sediment. U.S. Geo. Survey Report 87-514

Wilcock, P., S. Kenworthy, and J. Crowe, ( 2001). Experimental study of the transport of mixed sand and gravel. Water Resources Res. 12: 3349-3358 